\title{
Fungal Development and Induction of Defense Response Genes During Early Infection of Wheat Spikes by Fusarium graminearum
}

\author{
Clara Pritsch, ${ }^{1}$ Gary J. Muehlbauer, ${ }^{1}$ William R. Bushnell, ${ }^{2,3}$ David A. Somers, ${ }^{1}$ and \\ Carroll P. Vance ${ }^{1,4}$ \\ ${ }^{1}$ Department of Agronomy and Plant Genetics, University of Minnesota; ${ }^{2}$ Department of Plant Pathology, \\ University of Minnesota; ${ }^{3}$ Cereal Disease Laboratory, Agricultural Research Service, U.S. Department \\ of Agriculture; and ${ }^{4}$ Plant Science Research Unit, Agricultural Research Service, U.S. Department of \\ Agriculture, University of Minnesota, St. Paul 55108, U.S.A.
}

Accepted 8 October 1999.

\begin{abstract}
Fusarium head blight (FHB) of wheat is a crippling disease that causes severe economic losses in many of the wheat-growing regions of the world. Temporal patterns of fungus development and transcript accumulation of defense response genes were studied in Fusarium graminearum-inoculated wheat spikes within the first 48 to $76 \mathrm{~h}$ after inoculation (hai). Microscopy of inoculated glumes revealed that the fungus appeared to penetrate through stomata, exhibited subcuticular growth along stomatal rows, colonized glume parenchyma cells, and sporulated within 48 to 76 hai. No major differences in the timing of these events were found between Sumai 3 (resistant) and Wheaton (susceptible) genotypes. In complementary experiments, RNA was extracted from spikes at several time intervals up to 48 hai and temporal expression patterns were determined for defense response genes encoding peroxidase, PR-1, PR-2 ( $\beta$-1,3-glucanase), PR-3 (chitinase), PR-4, and PR-5 (thaumatin-like protein). In both genotypes, transcripts for the six defense response genes accumulated as early as 6 to 12 hai during $F$. graminearum infection and peaked at 36 to 48 hai. Greater and earlier PR4 and PR-5 transcript accumulation was observed in Sumai 3, compared with Wheaton. Our results show that the timing of defense response gene induction is correlated with $F$. graminearum infection.
\end{abstract}

Fusarium head blight (FHB) caused by Fusarium graminearum Schwabe (teleomorph Gibberella zeae (Schwein.) Petch) is a re-emerging and devastating disease affecting all classes of wheat and other small grains (McMullen et al. 1997). In the U.S., economic losses in 1993 alone surpassed \$1 billion (McMullen et al. 1997), making it

Corresponding author: Carroll P. Vance; E-mail: vance004@tc.umn.edu

Minnesota Agricultural Experimental Station paper no. 99-1-13-0126, Scientific Journal series.

This article is in the public domain and not copyrightable. It may be freely reprinted with customary crediting of the source. The American Phytopathological Society, 2000. one of the greatest single-year losses due to any plant disease in North America. FHB reduces grain quality through destruction of starch and protein (Sutton 1982) and by accumulation of mycotoxins such as deoxynivalenol (DON), a vomitoxin, and the estrogenic zearalenone (Tuite et al. 1990; Bai and Shaner 1994).

Wheat spikes are susceptible to $F$. graminearum infection for a short period of time (10 to 20 days) from anthesis through the soft dough stage of kernel development (Schroeder and Christensen 1963). Primary infection occurs when ascospores (sexual spores) or macroconidia (asexual spores) released from soilborne debris and infected hosts are deposited on or inside flowering spikelets at conducive temperature and humidity. The classical model for F. graminearum colonization of wheat spikes indicates that infection is initiated on dead anthers (either extruded or caught between floral bracts), followed by hyphal penetration of the ovary and eventual infection of the floral bracts including glume, palea, and lemma (Adams 1921; Dickson et al. 1921; Pugh et al. 1933; Esau 1965). Although direct fungal penetration through the outer faces of floral bracts has been reported (Atanasoff 1920; Tu 1930; Bennett 1931; Ireta-Moreno and Bekele 1989; Boshoff et al. 1996), the initial steps in infection of wheat spikes have not been well documented.

Resistance mechanisms to FHB in wheat are classified as either passive or active (Mesterhazy 1995). Passive mechanisms are associated with phenotypic traits such as plant height, presence of awns, spikelet density, and time to flowering. Active mechanisms include five different components: (i) resistance to initial infection, also called Type I resistance; (ii) resistance to spread of infection or Type II; (iii) resistance to kernel infection or Type III; (iv) tolerance or Type IV; and (v) resistance to mycotoxin accumulation or Type $\mathrm{V}$ (Schroeder and Christensen 1963; Wang and Miller 1988; Mesterhazy 1995). The biochemical and molecular bases for resistance have not been established; however, putative mechanisms operating in Type $\mathrm{V}$ resistance have been proposed (Miller et al. 1986).

Although the genetics of FHB resistance in wheat are not fully understood, both polygenic (Bai and Shaner 1994) and oligogenic (Singh et al. 1995; Van Ginkel et al. 1996) inheri- 
tance have been reported. Waldron et al. (1999) associated five genomic regions with FHB Type II resistance, three derived from a resistant parent (Sumai 3) and two derived from a susceptible parent (Stoa). Recently, a major locus explaining $60 \%$ of the variation for FHB resistance in a Sumai 3-derived line was identified with molecular markers (Bai et al. 1999). This knowledge may allow the design of isolines differing at this particular genomic region, but these are not yet available.

Defense response genes, including genes encoding pathogenesis-related proteins (PRs), have been associated with the resistance reaction of numerous plant-pathogen interactions (Bowles 1990; Dixon and Lamb 1990; Cutt and Klessig 1992; Muradov et al. 1993; Hammond-Kosak and Jones 1996). Although expression of these genes during infection of leaves (Boyd et al. 1994; Clark et al. 1995), roots (Valè et al. 1994), coleoptiles (Stevens et al. 1996), and germinating seeds (Casacuberta et al. 1991; Cordero et al. 1992) is well documented, little information exists for a similar response in infected floral organs. Expression of PR genes in healthy floral tissue has been noted (Lotan et al. 1989; Neale et al. 1990); however, these reports suggest that floral PR gene expression is under developmental control. The induction of defense response transcripts in wheat spikes infected with $F$. graminearum has not been documented. Moreover, an association between a molecular response and resistance to FHB has not been established.

A better understanding of the underlying nature of the interaction between $F$. graminearum and wheat would be facilitated by characterizing early infection events in relation to the expression pattern of defense response genes in infected spikes. Such an approach may define targets for improving disease resistance. The objective of this work was to correlate temporal patterns of early events of $F$. graminearum infection on glumes from resistant (Sumai 3) and susceptible (Wheaton) wheat genotypes to transcript accumulation of six defense response genes encoding peroxidase, PR-1, PR-2 ( $\beta$-1,3-glucanases), PR-3 (chitinase), PR-4, and PR-5 (thaumatin-like protein).

\section{RESULTS}

\section{Fungal invasion and sporulation.}

To assess early events in $F$. graminearum infection of wheat spikes, we focused our efforts on infection of glumes. Glumes are floral bracts located in pairs at the base of each spikelet (Fig. 1; Esau 1965). The glumes partially enclose the two to five florets of the spikelet. Sumai 3 (resistant) and Wheaton (susceptible) wheat spikes were spray inoculated at anthesis with a spore suspension of $F$. graminearum. Glumes from inoculated spikes were sampled within the first $76 \mathrm{~h}$ after inoculation (hai) and examined by either scanning electron microscopy (SEM) or light microscopy (Figs. 2 and 3).

Macroconidia of $F$. graminearum germinated within 6 to 12 hai on the abaxial (inoculated) face of the glume (Fig. 2A). By 12 to 24 hai, hyphae were evident and frequently contacted stomata (Fig. 2B). These observations suggested that penetration could occur through these openings. The primary hyphae were uniformly thin and initially unbranched. Similar observations were made at 36 hai (data not shown). Direct penetration of epidermal cells by hyphae growing on the surface of the glume was not observed by SEM. At 48 to 76 hai, but not earlier, thickened, branched hyphae exhibited a coralloid structure and predominately developed along stomatal rows (Fig. 2C,D). Similar thickened hyphae in glumes sampled at the same time intervals (48-76 hai; Fig. 2E) were observed by SEM in subcuticular locations. Conidiophores with developing macroconidia (Fig. 2F) were evident by 48 to 76 hai on the surface of the glumes, indicating the fungus had quickly completed one asexual cycle on these tissues. Fully developed conidia were also observed at this time (48 to 76 hai; data not shown).

Penetration and fungal colonization within glume tissues were studied. To examine fungal penetration and colonization within glumes, we collected glumes within 76 hai. Glumes were cross-sectioned, stained with the fluorochrome Calcofluor, and examined with an epifluorescence microscope. For orientation, a Calcofluor-stained cross section of a watersprayed control glume is shown in Figure 3A. Strong, bright fluorescence was observed in healthy chlorenchyma tissue toward the abaxial (inoculated) surface, while weak fluorescence was observed in the epidermis and parenchyma. Chlorenchyma areas were preferentially located beneath stomata (Figs. 1C and 3A). Intensely stained hyphae could be readily seen on the surface of the abaxial (inoculated) epidermis of glumes (Fig. 3B,D). The presence of the fungus within glumes was evident at 48 to 76 hai (Fig. 3B-D) but not at earlier time intervals. Direct penetration of glume epidermis was not obvious. However, hyphal penetration through stomatal pores into substomatal chambers was evident (Fig. 3B). Unfortunately,
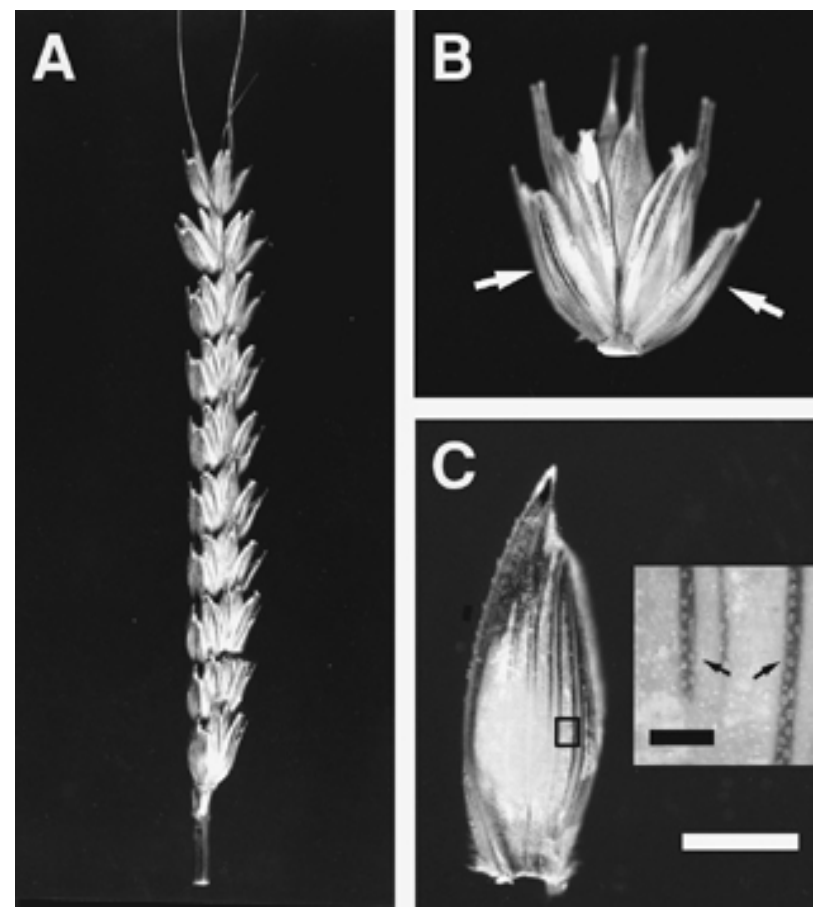

Fig. 1. Illustration of the glume in relation to other spike tissues in wheat. A, Wheat spike showing abaxial surfaces of spikelets (awns have been removed). B, Spikelet. Arrows point toward the two subtending glumes enclosing four florets. Each floret consists of an outer lemma and an inner palea enclosing the ovary and the anthers. Anthers are extruded from two florets. C, Glume. Dark longitudinal stripes correspond to chlorenchyma areas. Inset shows a higher magnification of longitudinal stripes (arrows). Stomatal rows are present over these areas. Scale bars A, $2 \mathrm{~cm}$; $\mathbf{B}$ and $\mathbf{C}, 250 \mu \mathrm{m} ; \mathbf{C}$ (inset), $150 \mu \mathrm{m}$. 
fluorescence of chlorenchyma obscured the view of hyphae in this tissue. In contrast, epidermis and parenchyma exhibited much lower levels of fluorescence than $F$. graminearum hyphae (Fig. 3B-D). Intracellular growth of $F$. graminearum hyphae within 48 to 76 hai was obvious in the epidermis but seen more clearly in ground parenchyma tissue (Fig. 3B-D). The intracellular hyphae were thick and usually unbranched. In some cases, coincident with abundant colonization of parenchyma tissues, mycelial development was observed on the opposite (adaxial) epidermal face (data not shown). The micrographs in Figures 2 and 3 depict the infection process observed in both Sumai 3 and Wheaton glumes. After approximately 30 to 35 glumes at each time interval-genotype combination in each of two experiments were examined, no major differences in either the timing or the development of the infection process were observed between the two genotypes.

\section{Transcript accumulation of defense response genes in $\boldsymbol{F}$. graminearum-infected wheat spikes.}

The wheat genotypes Sumai 3 and Wheaton were further investigated to determine the correlation between infection in spike tissues and timing of transcript accumulation of six defense response genes encoding peroxidase, PR-1, PR-2 ( $\beta-1,3$ glucanase), PR-3 (chitinase), PR-4, and PR-5 (thaumatin-like protein). In each of three experiments, wheat spikes at anthesis were sprayed with a $F$. graminearum spore suspension or water. One spike each was sampled from water-sprayed and $F$. graminearum-sprayed Sumai 3 and Wheaton at 0, 6, 12, 24, 36 , and 48 hai; therefore, a total of 24 spikes were sampled for each experiment. These time intervals corresponded to the sampling time intervals used in the histological work. Total RNA was prepared from whole spikes. Representative RNA gel blots from one of the three experiments are depicted in Figures 4 and 5. Data are presented as the average $( \pm$ SE) of relative signal intensities in three experiments, assigning a $100 \%$ value to the $F$. graminearum-inoculated Sumai 3 lane with the strongest hybridization intensity.

At 0 hai, basal levels of defense response gene transcripts were low to nondetectable (Figs. 4 and 5). Unexpectedly, transcripts for peroxidase, PR-1, PR-2, and, less prominently, PR3 , PR-4, and PR-5 accumulated in water control samples. In most cases, transcript accumulation started at 6 to $12 \mathrm{~h}$ after water spray treatment and either continued increasing up to 48 $\mathrm{h}$ or plateaued after the initial increase. In both genotypes, all the genes analyzed responded similarly to water spray treatments, with the exception of PR-5. PR-5 gene(s) from Sumai 3 were more responsive to water-sprayed controls than corresponding gene(s) from Wheaton. Although defense response transcripts accumulated in control samples, the overall abundance of transcripts for each of the genes analyzed was greater in samples inoculated with $F$. graminearum than in water controls (Figs. 4 and 5). In the results that follow, response to infection refers to transcript levels higher than water controls.

In response to infection, transcripts of all the six defense response genes accumulated as early as 6 or 12 hai (Figs. 4 and 5). These time intervals coincided with conidial germination over the surface of the glume and hyphae contacting stomata. Accumulation of transcripts continued to increase in both genotypes until 36 to 48 hai. At these time intervals, the highest levels of defense response gene transcripts coincided with development of thickened hyphae along stomatal rows, with intracellular hyphal growth in parenchyma tissue, and with fungal sporulation. In inoculated (resistant) Sumai 3, transcript abundance for all defense genes continued to increase up to 48 hai, except for PR-4, which plateaued after 36 hai. In inoculated (susceptible) Wheaton, on the other hand, highest transcript levels occurred at 36 hai but declined by 48 hai. This decline by 48 hai in Wheaton was consistently observed in all three experiments. At 48 hai, transcript levels for all genes analyzed were consistently lower in Wheaton samples, compared with Sumai 3 samples.

Peroxidase, PR-1, PR-2, and PR-3 transcripts (Fig. 4) accumulated abundantly in both genotypes. Peroxidase transcript levels in both genotypes were observed as early as 6 hai, and continued to accumulate until 36 to 48 hai. Although peroxidase transcript levels were somewhat higher in Wheaton than Sumai 3 at 36 hai in the experiment shown in Figure 4, the two genotypes did not differ in the second experiment (data not shown). Nevertheless, by 48 hai, peroxidase levels declined in Wheaton but remained high in Sumai 3. The maximum levels of peroxidase transcripts in inoculated tissues of Sumai 3 and Wheaton were seven- and 11-fold higher, respectively, than the levels observed in water controls. PR-2 mRNAs began to accumulate at 6 hai in Sumai 3 and Wheaton. The maximum levels of PR-2 transcripts from inoculated samples of Sumai 3 and Wheaton were three- and fivefold higher, respectively, than those of water controls. PR-1 transcript levels increased slightly in response to infection at 6 to 12 hai, but several-fold by 24 hai. This result was observed in both genotypes. (Fig. 4). At 48 hai, PR-1 transcript levels of Sumai 3 samples were higher than those from Wheaton. The maximum levels of PR-1 transcripts of inoculated samples of Sumai 3 and Wheaton were seven- and threefold higher, respectively, than those of water controls. The PR-3 pattern of transcript accumulation was similar at 6 to 36 hai in the two genotypes (Fig. 4). PR-3 mRNAs began to accumulate in response to infection at 12 to 24 hai and continued to increase up to 36 to 48 hai. Maximum levels of PR-3 transcripts for both genotypes were three- to fourfold higher than levels of water controls.

For PR-4 and PR-5, major differences in transcript accumulation between genotypes were found (Fig. 5). PR-4 transcript accumulation became evident by 12 hai in Sumai 3 but not until 24 hai in Wheaton. At 24 to 48 hai, transcript levels in Sumai 3 were higher than in Wheaton. In a similar pattern, PR-5 transcript started accumulating by 6 hai in Sumai 3 and at 24 hai in Wheaton. PR-5 mRNA levels in Sumai 3 were higher than in Wheaton at 12 to 48 hai. At 48 hai, maximum levels of PR-4 and PR-5 transcripts were observed in Sumai 3, corresponding to 1.7- and threefold the transcript levels in Wheaton, respectively. Maximum levels of PR-4 transcripts were 12- and fivefold higher for Sumai 3 and Wheaton, respectively, than those of water controls. For both genotypes, PR-5 transcripts of inoculated samples were three- to fourfold higher than those of water controls.

\section{DISCUSSION}

FHB is a serious disease of wheat spikes caused by $F$. graminearum. In this report, we extend the understanding of FHB by describing the early steps of fungal development during infection of wheat glumes in relation to the molecular 
response of spike tissues to infection. This report documents the earliest steps in fungal development in glume tissue within 76 hai (Figs. 2 and 3). We show that hyphal penetration appeared to occur through glume stomata. We also present evidence for two patterns of colonization, including subcuticular hyphae on inoculated epidermis (Fig. 2C and E) and abundant intracellular colonization of parenchyma tissues (Fig. 3C,D).
These events were coincident with sporulation on the surface of the glume (48 to 76 hai). We also show that both resistant and susceptible genotypes were successfully colonized by $F$. graminearum within 48 to 76 hai (Figs. 2 and 3) and that, as a response to infection, transcripts of several defense response genes encoding peroxidase, PR-1, PR-2, PR-3, PR-4, and PR5 accumulated in wheat spike tissues (Figs. 4 and 5). In addi-
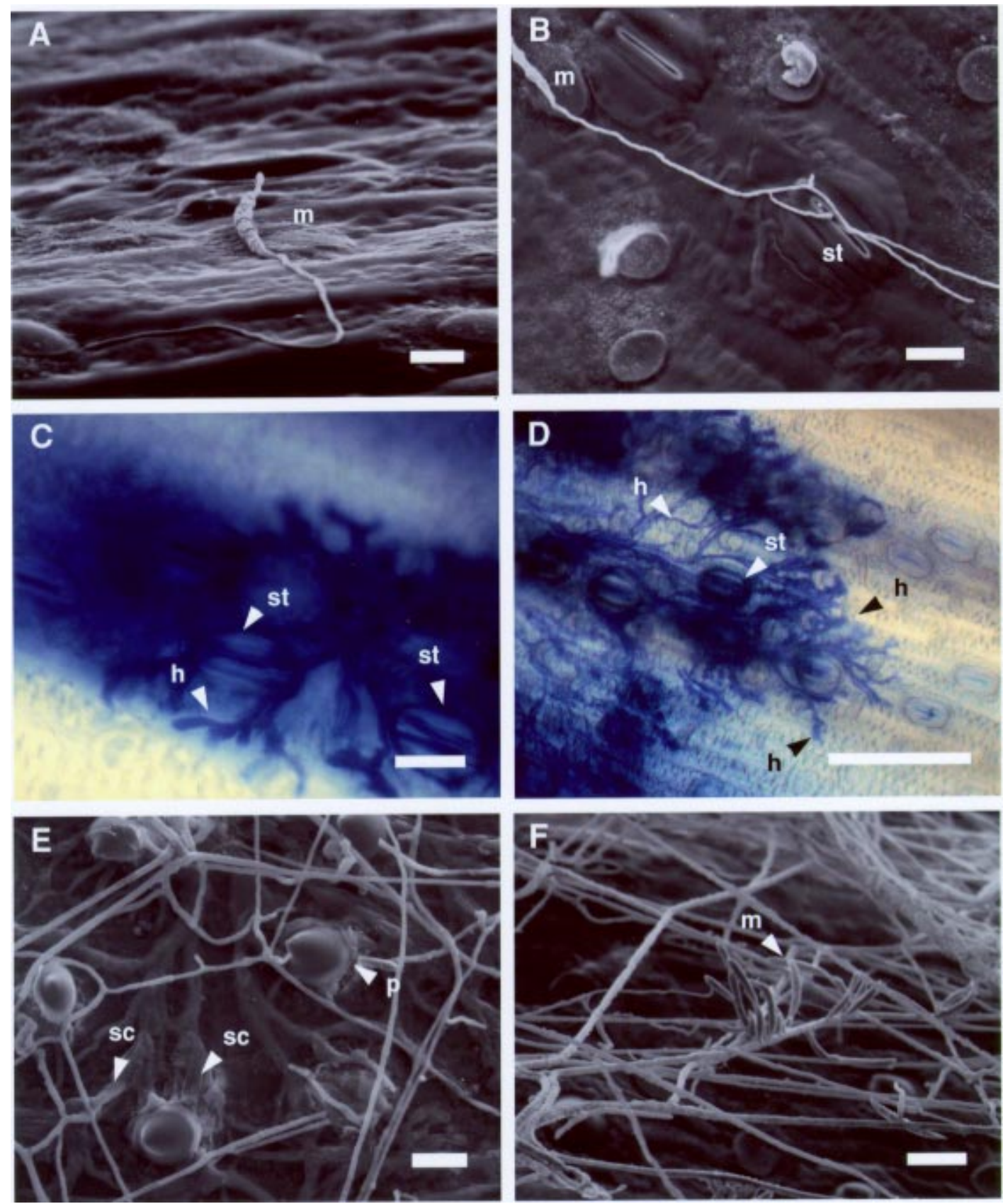

Fig. 2. Early infection events of Fusarium graminearum on the abaxial surface of wheat glumes. Wheat spikes were spray inoculated with a spore suspension $\left(2 \times 10^{6}\right.$ conidia per $\left.\mathrm{ml}\right)$ and glumes were sampled within $76 \mathrm{~h}$ after inoculation (hai). A-B and E-F, Scanning electron microscopy (SEM) micrographs of abaxial surfaces of inoculated glumes. C-D, Bright field micrographs of abaxial surfaces in specimens stained with cotton bluelactophenol. A, Macroconidium germinating on a glume from the cv. Wheaton (6 hai). B, Hyphae contacting a stoma, cv. Wheaton (12 hai). C, Area of a glume containing stomatal rows from Sumai 3 (48 hai). Thickened and ramified hyphae with coralloid branching are present. D, Area of a glume containing stomatal rows from Sumai 3. Thickened hyphae with abundant coralloid branching ( 76 hai). E, Subcuticular hyphae developing on a glume from Sumai 3 beneath thinner hyphae growing above cuticle surface (48 hai). This view shows silicon-filled papilla cells found on abaxial surfaces of the glume. F, Macroconidia on a conidiophore developing on a glume from Wheaton (76 hai). Abbreviations: h, hypha; m, macroconidium; $\mathrm{p}$, papilla cell; sc, subcuticular hyphae; st, stoma. Bars = D, $40 \mu \mathrm{m} ; \mathbf{B}, \mathbf{E}, \mathbf{F}, 20 \mu \mathrm{m} ; \mathbf{A}, \mathbf{C}, 10 \mu \mathrm{m}$. 
tion, we show that accumulation of PR-4 and PR-5 transcripts are greater and earlier in the resistant genotype than in the susceptible genotype (Fig. 5).

\section{F. graminearum colonizes wheat glumes within 48 to 76 hai.}

Conidial germination on glume surfaces by 6 hai (Fig. 2A) is similar to the timing of in vitro germination $(7 \mathrm{~h})$ of washed macroconidia of $F$. graminearum in the absence of exogenous organic carbon at a similar temperature (Cappellini and Peterson 1971). It is not known whether specific compounds from the host are required to trigger and to sustain conidia germination in planta; however, the similarity of our results to those of Cappellini and Peterson (1971) suggests that host compounds may not play an important role in spore germination.

Glume stomata appeared to be penetrated by hyphae (Figs. $2 \mathrm{~B}$ and $3 \mathrm{~B}$ ). These observations suggest that glume stomata are one of the early entry points of $F$. graminearum. This result constitutes the first documented report of stomatal penetration in FHB and is consistent with a preliminary report indicating $F$. graminearum penetration through stomata in wheat paleas and lemmas (Boshoff et al. 1996). A similar mode of penetration was found in wheat coleoptiles infected with ei- ther F. culmorum or F. nivale (Malalasekera et al. 1973) and has been reported for several Fusarium spp. responsible for cortical rot diseases (Pennypacker 1981). Direct penetration of the glume epidermal cells was not observed in our studies. Glume epidermal cells may be highly resistant to penetration because the thick, crenulated cell walls, and occasionally cell lumina, are highly silicified (Hodson and Sangster 1988a, 1988b). Nevertheless, we found hyphae within epidermal cells (Fig. 3B). Whether these hyphae originated from penetrated stomata or from infection elsewhere remains to be established.

Spatially, stomata are found in rows along the length of the abaxial face of the glume. These stomatal rows are located immediately above narrow, longitudinal, green bands corresponding to chlorenchyma areas where active photosynthesis takes place (Figs. 1C and 3A; Percival 1921; Hodson and Sangster 1988a). Therefore, fungal penetration through glume stomata provides the pathogen direct access to chlorenchyma. Although fungal colonization of chlorenchyma tissue was not clearly observed in our studies, due to fluorescence of chlorenchyma that obscures the view of Calcofluor-stained hyphae (Fig. 3A-D), abundant hyphae were previously observed in chlorenchyma of heavily infected glumes, rachis, and culms (Pugh et al. 1933). Accordingly, we suspect that chloren-
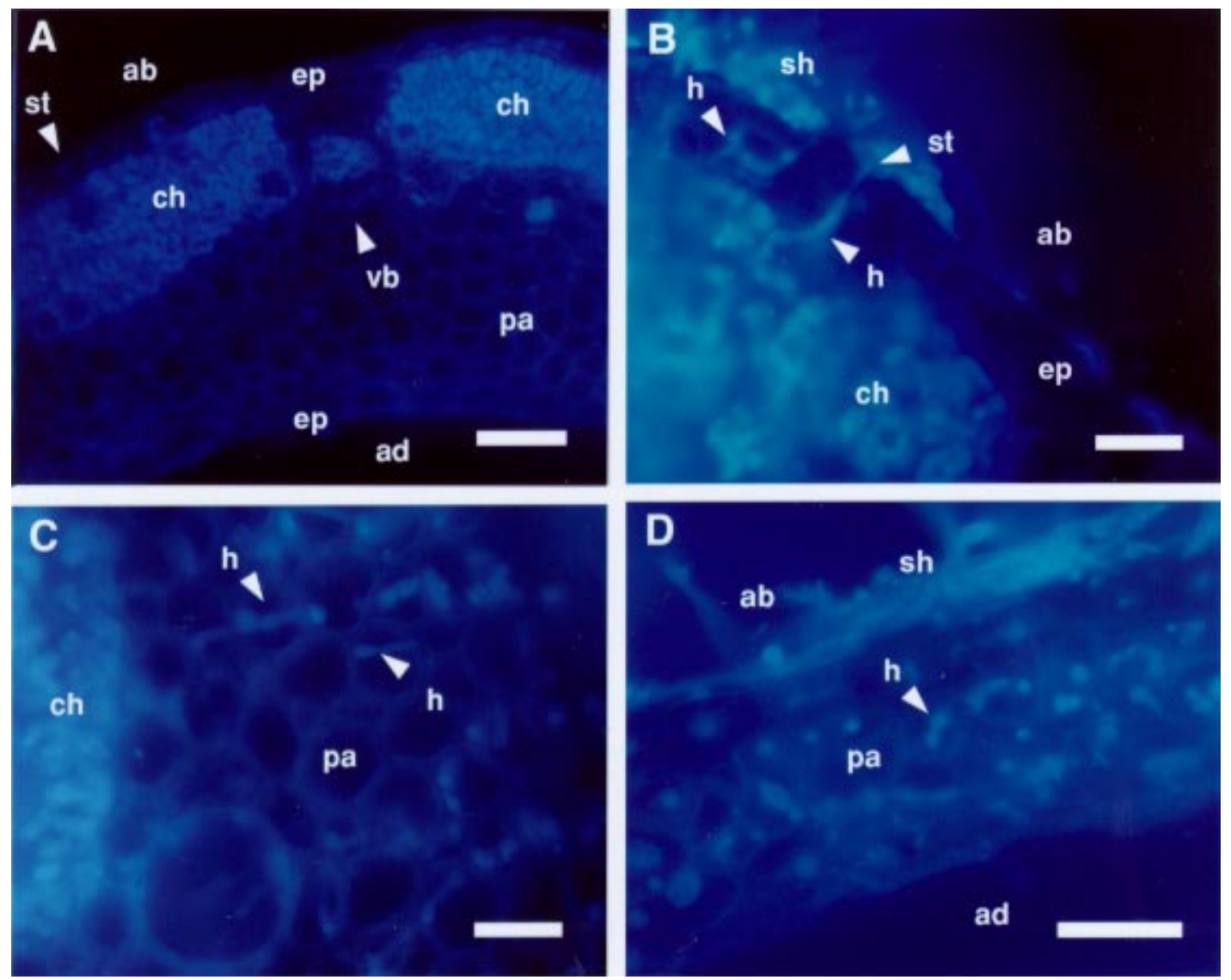

Fig. 3. Calcofluor-stained cross sections of Fusarium graminearum-inoculated wheat glumes. A, Control (water-sprayed) glume from Sumai 3 ( 76 h after treatment). Strong, bright fluorescence occurs in chlorenchyma toward the abaxial face while less intense fluorescence is detected in parenchyma toward the adaxial face. B, Abundant superficial hyphae developing on the abaxial (inoculated) face. Also shown are a hypha invading an epidermal cell and a hypha penetrating through a stomatal pore and substomatal chamber. Fluorescence of the chlorenchyma obscures the view of fungal growth beneath the stoma, cv. Wheaton ( $76 \mathrm{~h}$ after inoculation [hai]). C, Abundant fungal colonization (intracellular) of parenchyma tissue is visible because hyphae are brighter than the parenchyma cells, cv. Wheaton (48 hai). D, Abundant superficial hyphae on the abaxial surface and intracellular colonization of parenchyma, Sumai 3 (76 hai). Abbreviations: ab, abaxial surface; ad, adaxial surface; ch, chlorenchyma; ep, epidermis; h, hypha; pa, parenchyma; sh, superficial hyphae; st, stoma; vb, vascular bundle. Bars = A, $25 \mu \mathrm{m} ; \mathbf{B}-\mathbf{D}, 10 \mu \mathrm{m}$. 
chyma tissue is a target for $F$. graminearum early infection. Interestingly, a similar pathway of invasion of wheat glumes by way of stomata and chlorenchyma was reported for Tilletia indica, causal agent of Karnal bunt of wheat (Goates 1988).

Abundant fungal colonization within glume tissues was observed at 48 to 76 hai in Calcofluor-stained glume cross sections (48 to 76 hai; Fig. 3B-D). The observation of hyphae growing within parenchyma cells is in agreement with previous reports concerning wheat floral bracts (Pugh et al. 1933; Ireta-Moreno and Bekele 1989) and rachis (Schroeder and Christensen 1963). Ground parenchyma tissue in the glume is characterized by cells with very thick, lignified cell walls, and by the absence of intercellular spaces (Fig. 3A,C,D). Hyphae growing across adjacent parenchyma cells may grow through pits in the thick cell walls, as suggested by Pugh et al. (1933) for $F$. graminearum-infected wheat glumes and by Malalasekera et al. (1973) for F. culmorum-infected wheat coleoptiles. Compelling evidence of fungal growth through pit cell walls of glume parenchyma cells was presented by Koga (1995) when describing Pyricularia oryzae infection of rice glumes. Further investigation is needed to elucidate the mechanisms of $F$. graminearum colonization of glume parenchyma cells. Although intercellular hyphal growth was previously reported by Pugh et al. (1933) in rachis and culm paren- chyma tissues, we found no evidence of it in our studies of glumes. It is noteworthy that anatomical differences found in floral bract parenchyma among cultivars of wheat and barley, such as size of the cells and thickness of the cell walls, correlated to differences in the levels of resistance to $F$. graminearum (Ikeda et al. 1955).

\section{F. graminearum produces subcuticular hyphae.}

In this study, we report subcuticular colonization of wheat glumes by $F$. graminearum (Fig. $2 \mathrm{E}$ ) at 48 to 76 hai. This finding is the first documented evidence for subcuticular growth by this pathogen. Other pathogens also exhibit subcuticular growth. For example, Colletotrichum heterostrophum (syn. Helminthosporium maydis; Wheeler 1977), Phomopsis leptostromiformis (Williamson et al. 1991), and F. nivale (Malalasekera et al. 1973) exhibited subcuticular growth on leaves, and Pyricularia oryzae exhibited subcuticular growth on glumes (Koga 1995). In general, following primary penetration of host tissues, fungi exhibiting subcuticular growth develop flat, branched hyphae within the subcuticular space defined between the cuticle and the epidermal cell walls. The thick, ramified hyphae observed by light microscopy along stomatal rows (Fig. 2C,D) presented the same coralloid structure as the subcuticular hyphae of Phomopsis lepto-
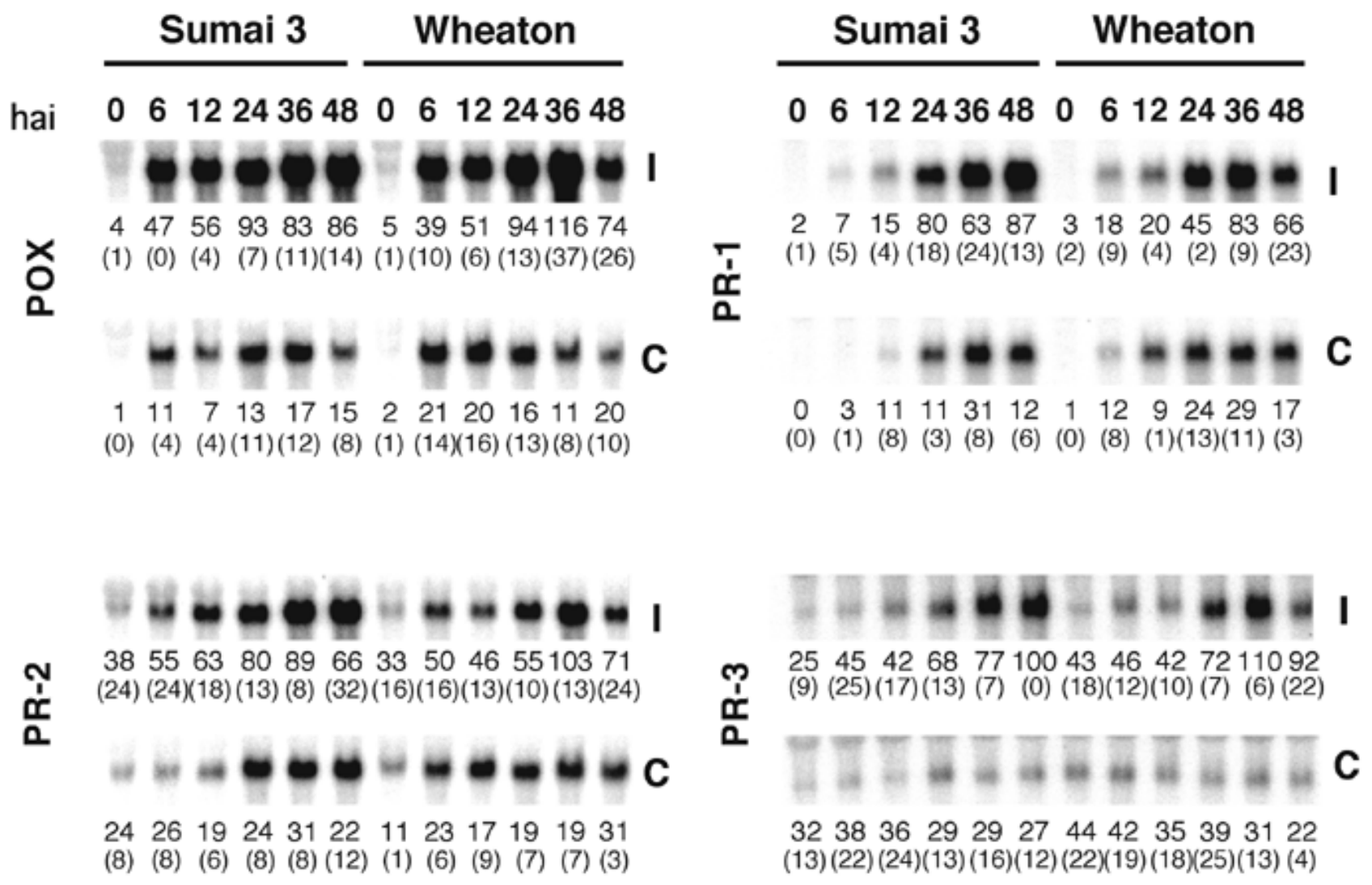

Fig. 4. Time course of peroxidase, PR-1, PR-2, and PR-3 transcript accumulation in Fusarium graminearum-inoculated (I) or water-sprayed control (C) wheat spikes from cvs. Sumai 3 (resistant) and Wheaton (susceptible). Total RNA was isolated from whole spikes at 0 to $48 \mathrm{~h}$ after inoculation (hai). RNA gel blot analysis (15 $\mu \mathrm{g}$ of total RNA per lane) was performed with a wheat cDNA encoding peroxidase, POX, (plasmid pOX381; Rebman et al. 1991a), wheat PR-1-2 cDNA, PR-1, (EMBL AJ007349; Molina et al. 1999), barley $\beta$-1,3-glucanase cDNA, PR-2, (pBH72.I7; Gregersen et al. 1997), and barley acidic chitinase Class II cDNA, PR-3, (pHvCht2a, EMBL X78671; Gregersen et al. 1997). Quantification of radioactivity signals was performed as described in Materials and Methods. Numbers below each individual blot correspond to the average of three experiments of the percentage of maximal signal intensities observed in F. graminearum-inoculated Sumai 3 samples. Peroxidase data correspond to the average of two experiments. Numbers in parentheses represent standard error of the mean. 
stromiformis infecting narrow-leafed lupins (Williamson et al. 1991). We do not know how $F$. graminearum penetrated the cuticle of wheat glumes. Reported modes of penetration of the cuticle include enzymatic degradation (Venturia inaequalis; Köller et al. 1991) and mechanical penetration (Pyricularia oryzae; Koga 1995). Interestingly, Wheeler (1977) reported for $C$. heterostrophum-colonizing maize leaves that most of the penetrations and subcuticular development occurred adjacent to stomatal apparatus, i.e., either between a guard cell and a subsidiary cell from the stomatal complex or between a subsidiary cell and the adjacent epidermal cell. Whether the development of subcuticular hyphae of $F$. graminearum along stomatal rows relates to sites of penetration near stomata remains to be determined. According to Wheeler (1977), subcuticular colonization may allow a secondary penetration and spread of the pathogen. Degradation of polymeric carbohydrates of the epidermal cell wall and the cutin may serve as an energy source for the pathogen (Wagner et al. 1988; Koga 1995).

\section{Glumes from resistant and susceptible genotypes were similarly colonized.}

Under our experimental conditions, no major differences were found between Sumai 3 and Wheaton for initial infection

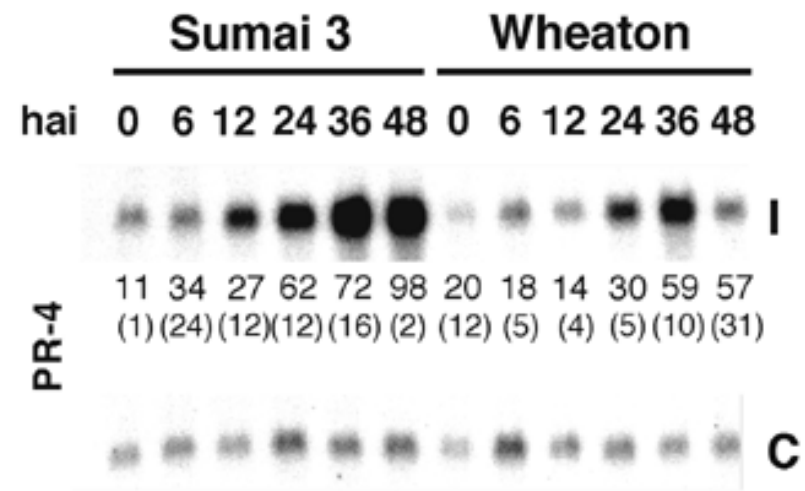

$\begin{array}{llllllllllll}17 & 23 & 20 & 14 & 13 & 8 & 13 & 14 & 10 & 13 & 12 & 23\end{array}$ (6) (10) (11) (2) (2) (4) (6) (5) (1) (1) (5) (8)

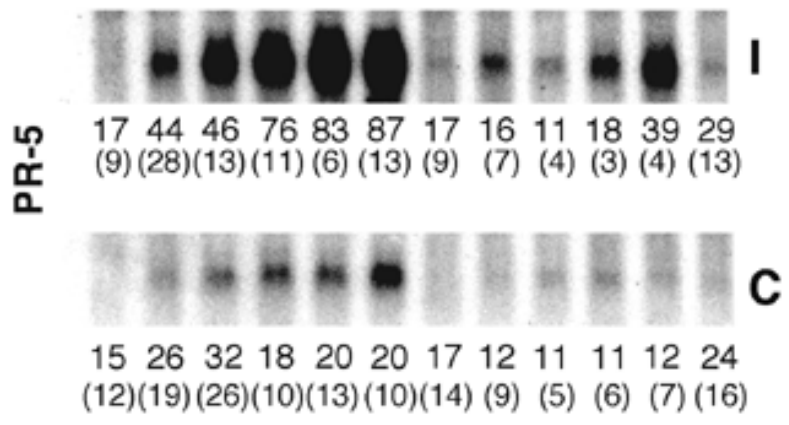

Fig. 5. Differential accumulation of PR-4 and PR-5 mRNAs in Fusarium graminearum-inoculated (I) or water-sprayed control (C) wheat spikes from cvs. Sumai 3 (resistant) and Wheaton (susceptible). Blots were hybridized with barley cDNAs encoding PR-4 (pBH72-F6, EMBL Y10814; Gregersen et al. 1997) and an acidic PR-5 (thaumatin-like protein, pBH72-C6; Gregersen et al. 1997). Further details are explained in the Figure 4 caption. and invasion of glumes. Sumai 3 exhibits a high level of Type II resistance, i.e., resistance to spread of infection (Wilcoxson et al. 1992). Although there are reports of Sumai 3 exhibiting Type I resistance, i.e., resistance to initial infection, it is generally believed that Type II resistance is the predominant form of resistance exhibited by Sumai 3 (Wang and Miller 1988; Wilcoxson et al. 1992). However, under certain environmental conditions, the resistance in Sumai 3 is unstable, resulting in susceptibility to the pathogen (Wang and Miller 1988). Type I resistance is typically scored as the percentage of spikes showing head blight symptoms under natural inoculation (Wang and Miller 1988). Our spray-inoculated experiments were designed to evaluate Type I resistance but not Type II resistance. Type I or Type II resistance does not provide information about resistance to initial invasion at the cellular level. Wheaton does not possess a high level of either Type I or Type II resistance (Wilcoxson et al. 1992). Therefore, the similarity in initial infection and invasion of glumes between the Type II resistant Sumai 3 genotype and the susceptible Wheaton genotype is not surprising. Whether other spike tissues of Sumai 3 and Wheaton genotypes display similar susceptibility remains to be established. In spite of the similarities of fungal infection in the two genotypes, we saw differences in transcript accumulation in two of the defense response genes.

Defense response gene transcripts accumulate in response to $F$. graminearum infection in wheat spikes.

Wheat spikes responded rapidly at the molecular level to $F$. graminearum infection. Accumulation of peroxidase, PR-1, PR-2, PR-3, PR-4, and PR-5 transcripts in both the resistant and the susceptible genotype correlated with progress of fungal infection (Figs. 4 and 5). The earliest responses occurred at 6 hai with peroxidase and PR-5, at the time of spore germination on the surface of the glumes. In the 0 to 48 hai time frame we examined, maximal accumulation of all gene transcripts analyzed occurred at 36 to 48 hai, coincident with abundant, ramified hyphae growing along stomatal rows, with intracellular colonization of parenchyma cells, and with sporulation (Figs. 2 and 3). These patterns of expression present in both resistant and susceptible genotypes are typical for genes considered markers of a general host response to infection. Similar observations were noted previously for barley leaves infected with Erysiphe graminis (Clark et al. 1993, 1995).

Transcript accumulation of PR-4 and PR-5 was greater in the resistant genotype (Sumai 3) than in the susceptible genotype (Wheaton) (Fig. 5). Interestingly, these transcripts accumulated differently although $F$. graminearum colonization of wheat glumes was similar in both genotypes. We do not know whether, in addition to the participation of PR-4 and PR-5 in a general defense response to infection, their expression is part of a resistant-dependent defense response (Hammond-Kosak and Jones 1996) operating in the resistant genotype Sumai 3. The actual participation of these wheat genes in a resistantdependent defense response could be assessed by a number of approaches. For example, studies similar to the ones reported here might include a range of genotypes with different sources and levels of resistance. Transcripts of PR-4 and PR-5 would consistently accumulate more in resistant than in susceptible lines if an association with resistance exists. In addition, 
isogenic lines differing in FHB resistance could be used to show that resistance and transcript accumulation are closely associated. The identification by molecular markers of a major quantitative trait locus (QTL) for FHB resistance in a Sumai 3-derived line (Bai et al. 1999) may allow the development of such lines for further studies.

Several lines of evidence support a role for PR-5 in resistance mechanisms in cereals (Lin et al. 1996; Schaffrath et al. 1997; Morris et al. 1998). Accumulation of PR-5 transcripts in wheat correlated with the onset of local acquired resistance to powdery mildew induced by inoculation with the nonpathogen Erysiphe graminis f. sp. hordei (Schweizer et al. 1989; Rebman et al. 1991b). In rust-maize interactions, PR-1 and PR-5 genes are considered indicators of the resistance reaction (Morris et al. 1998). The stronger induction of transcripts for these genes observed in incompatible, compared with compatible, interactions correlates with the onset of the hypersensitive response and the actual arrest of lesion growth. Also, PR-5 proteins from several plant species exhibited in vitro antifungal activity (Vigers et al. 1992). Finally, several defense response genes have been recently mapped in wheat, as part of a candidate gene approach to mapping QTLs for disease resistance. In this study, genes encoding thaumatin-like protein (PR-5) mapped within four previously identified QTLs for leaf rust resistance (Faris et al. 1999).

Similarly, induction of PR-4 proteins in a general response to infection has been reported although a specific function for PR-4 proteins has not been assigned. Wheat PR-4 proteins 'wheatwin1' and 'wheatwin2', while developmentally regulated in healthy wheat grains (Caruso et al. 1996), are pathogenesis-induced in $F$. culmorum-infected wheat seedlings (Caruso et al. 1999). Both wheatwin1 and wheatwin2 proteins have in vitro antifungal activity against $F$. culmorum and $F$. graminearum (Caruso et al. 1999). Moreover, in barley, PR-4 transcripts have been found to accumulate in powdery mildew-infected leaves (Gregersen et al. 1997). Our results show, for the first time, accumulation of transcripts homologous to the barley PR-4 gene in infected spikes and that higher and earlier accumulation of these transcripts occurred in the resistant genotype. We do not know whether these transcripts corresponded to the 'wheatwin' proteins described by Caruso (1996, 1999) or to other members of the PR-4 family.

Because we used the coding region of defense response genes as probes, our interpretation of transcript accumulation in response to $F$. graminearum is conservative. Although the probes were selected because they are pathogen inducible in barley and wheat, they could reflect expression of more than one gene from each gene family. Gene-specific expression could be assessed with the $5^{\prime}$ or $3^{\prime}$ untranslated regions from gene sequences used as probes. Nevertheless, we detected large increases in all of the defense response gene transcripts examined. Thus, there is little question that some members of these gene families are highly induced during FHB development.

Transcripts of all defense response genes tested accumulated at low levels in water-sprayed spikes. We further investigated this result by examining levels of transcripts of unsprayed spikes sampled from plants incubated under different conditions. Transcript accumulation was not related with developmental changes because unsprayed spikes collected $48 \mathrm{~h}$ after anthesis from plants growing in a growth chamber did not show accumulation of defense response mRNAs (data not shown). However, defense response transcripts did accumulate in unsprayed spikes sampled from plants that were incubated for $48 \mathrm{~h}$ in a dew chamber after the start of anthesis. These observations suggest that the humid and/or reduced light conditions present in the dew chamber, and not the water spray treatment, may be responsible for the low level of transcript accumulation observed in control samples.

Wheat spikes are composed of multiple tissues including glumes, lemmas, paleas, lodicules, ovaries, stigmas, anthers, rachis, rachillae, and awns (Fig. 1; Percival 1921; Esau 1965). Because we extracted total RNA from whole spikes, we do not know which spike tissue is the most responsive. Note that florets within each spikelet (Fig. 1) are only partially enclosed by glume tissues and several additional tissues are exposed to the sprayed inoculum. In our studies, infection probably also developed on exposed lemmas or extruded anthers. Specific localization of enhanced transcript accumulation awaits analysis of these individual tissues and/or in situ hybridization. In a preliminary experiment, we separated ovaries from the other bulk tissues of inoculated spikes, and evaluated peroxidase expression at 48 hai. Increased peroxidase mRNA did not occur in the ovary but did increase in bulk samples containing the remaining elements of the spikes (C. Pritsch, C. P. Vance, and G. J. Muehlbauer, unpublished results). These results indicate that further work is needed to elucidate more fully the molecular response to $F$. graminearum infection of wheat spikes.

\section{MATERIALS AND METHODS}

\section{Plant material.}

Two wheat (Triticum aestivum L.) genotypes with contrasting levels of resistance to Fusarium head blight (FHB) were used. Wheaton, a hard red spring cultivar from the midwestern U.S., is highly susceptible to FHB. Sumai 3 is a Chinese cultivar known for its Type I and II resistances to FHB (Wang and Miller 1988; Wilcoxon et al. 1993; Bai and Shaner 1994). Surface-sterilized wheat seeds were planted in 15.24$\mathrm{cm}$ pots with Strong-Lite germination mix (Pine Bluff, AR) at a rate of four plants per pots. Plants were grown in a controlled environment cabinet (Conviron PGV36, Pembina, ND), with a $16-\mathrm{h}$ photoperiod and $20 / 16^{\circ} \mathrm{C}$ day/night temperature. Cool, white fluorescent and supplementary incandescent lamp illumination was supplied at a total of $150 \mu \mathrm{E} \mathrm{s}^{-1}$ $\mathrm{m}^{-2}$. Mineral fertilization was applied twice with Nutricote Total (18-6-8) with Micronutrients, Type 70 (Brampton, Ontario, Canada), at emergence (Zadoks stage 11; Zadoks et al. 1974) and at elongation stage (Zadoks stage 31). At the elongation stage the secondary tillers were trimmed.

\section{Preparation of fungal inoculum, inoculation procedures, and sampling.}

Monosporic isolate $3 \mathrm{~A} 31$ of $F$. graminearum was used throughout. Cultures were initiated from a frozen macroconidia suspension on mung bean agar plates ( $40 \mathrm{~g}$ of mung beans per liter [wt/vol] in distilled water, boiled for $15 \mathrm{~min}$, and filtered through four layers of cheesecloth, supplemented with $1.5 \%$ agar [wt/vol]). They were incubated for 3 to 6 days at $25^{\circ} \mathrm{C}$ with a 12 -h photoperiod of cool, white fluorescent light. Spores were collected by washing the colonized agar surface of each plate with $3 \mathrm{ml}$ of distilled water and then filtering the 
spore suspension through four sterile cheesecloth layers. Spore counts were determined with a hemacytometer.

Wheat spikes at anthesis (6 to 7 weeks after germination; Zadoks stages 65-69; Zadoks et al. 1974), from each genotype were spray inoculated with a freshly prepared spore suspension of $2 \times 10^{6}$ macroconidia per $\mathrm{ml}$ in $0.04 \%$ (vol/vol) Tween 20 in water. Spraying was performed with an air brush (Model VL; Paasche Airbrush, Harwood Heights, IL) adjusted to a pressure of $82.8 \mathrm{kPa}$. Each spike retained an average of $500 \mu \mathrm{l}$ of spore suspension measured by weight $15 \mathrm{~min}$ after spraying. Following inoculation, the plants were placed in a dew chamber set at $21^{\circ} \mathrm{C}, 98 \pm 2 \%$ relative humidity, and permanent light $\left(5.7 \mu \mathrm{E} \mathrm{s}^{-1} \mathrm{~m}^{-2}\right)$ for $48 \mathrm{~h}$. As a control, spikes in the same stage of development were sprayed with water, and similarly placed in the dew chamber. Water-sprayed spikes were also covered with a plastic bag after spraying to prevent fortuitous fungal contamination in the dew chamber. Three experiments were conducted to assess defense response transcript accumulation. For RNA isolations, one spike each was sampled from water-sprayed and $F$. graminearum-inoculated Sumai 3 and Wheaton at 0, 6, 12, 24, 36, and 48 hai. Therefore, for each experiment, RNA was isolated from 24 spikes (two genotypes at six time intervals from two treatments). Combining all three experiments, a total of 72 spikes were sampled. Spikes sampled for RNA extraction were immediately frozen in liquid $\mathrm{N}_{2}$ and stored at $-70^{\circ} \mathrm{C}$.

Two experiments were conducted to examine the timing and pathways of infection of $F$. graminearum on wheat glumes. For histological evaluations, glumes from water-sprayed and $F$. graminearum-inoculated Sumai 3 and Wheaton were sampled at $6,12,24,36,48$, and 76 hai. Glumes sampled for histological observations were placed in contact with the appropriate fixative. Glumes were sampled from the same set of plants that were used for two of the experiments examining defense response transcript accumulation.

The amount of superficial colonization was preliminarily evaluated in two glumes per genotype at 48 and 76 hai by SEM. By 48 hai, a range of 4 to 14 and 8 to $18 F$. graminearum colonies per glume was observed in Wheaton and Sumai 3 glumes, respectively. By 76 hai, superficial mycelia were found in 60 and $100 \%$ of glume area for Wheaton and Sumai 3, respectively. By this time, and not earlier, mycelia became evident to the naked eye, a time coincident with appearance of symptoms of decoloration in some areas of the glumes.

\section{Lactophenol-cotton blue staining.}

Sampled glumes were fixed on paper towels moistened with 3:1 ethanol:glacial acetic acid ( $\mathrm{vol} / \mathrm{vol})$ to avoid displacement of spores or infection structures (Carver et al. 1991). Briefly, the adaxial, noninoculated faces of the glumes were placed in contact with the fixative for 1 week. Fixed glumes were boiled for $4 \mathrm{~min}$ in lactophenol:ethanol $(1: 2, \mathrm{vol} / \mathrm{vol})$ and mounted on glass slides in $100 \%$ glycerol for bright field observation with a Labophot microscope (Nikon, Garden City, NY). Ten to 15 glumes from each genotype-time interval combination were examined.

\section{Calcofluor staining.}

Fixed glumes as described in the previous section were stained with Calcofluor (Rohringer et al. 1977; Kuck et al.
1981). Calcofluor is a fluorochrome of the diamino-stilbenedisulfonate type that stains fungi in culture and during plant infection (Darken 1961; Rohringer et al. 1977). Briefly, fixed glumes were cleared with chloroform:methanol (2:1, vol/vol) for $16 \mathrm{~h}$, boiled in lactophenol:ethanol $(1: 2, \mathrm{vol} / \mathrm{vol})$ for $4 \mathrm{~min}$, and kept in this solution for 1 day. The glumes were then washed as recommended by Rohringer et al. (1977) and handsectioned transversally with a razor blade. The sections were then stained for 5 min with $0.3 \%$ solution of Calcofluor White M2R New (American Cyanamid, Bound Brook, NJ) in Tris/HCl $0.1 \mathrm{M}, \mathrm{pH} 8.5$ buffer. The specimens were washed three times in water (10 min each) and once in $25 \%$ aqueous glycerol (30 $\mathrm{min})$. The stained sections were mounted on glass slides in $100 \%$ glycerol and observed by epifluorescence microscopy with ultraviolet irradiation (Zeiss standard microscope equipped with an exciter filter G365; chromatic beam splitter FT 395; barrier filter LP 420). Ten to 15 glumes were sampled from each genotype-time interval combination and 15 to 20 hand cross sections were examined per glume.

\section{Scanning electron microscopy.}

Glumes were fixed overnight in $2.5 \%$ glutaraldehyde in $0.05 \mathrm{M}$ phosphate buffer, $\mathrm{pH} 7.2$ at $4^{\circ} \mathrm{C}$. Samples were rinsed three times in the phosphate buffer, 5 min each, and fixed for $1 \mathrm{~h}$ in buffered $1 \% \mathrm{OsO} 4$ at room temperature. Samples were then rinsed with water three times (10 min each), dehydrated in a graded series of ethanol (25 to $100 \%$ ) at room temperature, and dried with $\mathrm{CO}_{2}$ in a Ladd critical-point dryer (Ladd, Burlington, VT). The dried samples were affixed to aluminum stubs with conductive paint and then coated with goldpalladium alloy in a Kinney (KSE-2A-M) vacuum evaporator. The abaxial face of the glumes was examined with a Philips 500 scanning electron microscope (FEI, Hillsboro, OR) at 12 $\mathrm{kV}$. Digital images were acquired from SEM with NIH Image software (W. Rasband, NIH) by computer control of the electron beam scanning raster. Three glumes from each genotypetime interval combination were examined.

\section{RNA isolation and RNA gel blot analysis.}

For each experiment, 24 RNA samples were prepared from water-sprayed and $F$. graminearum-inoculated Sumai 3 and Wheaton spikes sampled at $0,6,12,24,36$, and 48 hai. One spike was used for each RNA isolation. Frozen samples of inoculated and noninoculated spikes were ground into fine powder in liquid $\mathrm{N}_{2}$, and total RNA was isolated by the $\mathrm{LiCl}$ precipitation procedure described by De Vries et al. (1982). Total RNA samples were fractionated in 1\% agarose/formaldehyde gels and the gel was blotted onto nylon membranes (Zeta-Probe; Bio-Rad, Hercules, CA). Prehybridizations and hybridizations of membranes were performed in $50 \%$ formamide at $42^{\circ} \mathrm{C}$ according to the membrane manufacturer's instructions. From each experiment, six sets of blots were made. Each set included two blots, one containing F. graminearuminoculated samples from both genotypes and the other containing controls. Each membrane was probed once with one of the cDNA clones. Inserts of cDNA clones were isolated from preparative agarose gel electrophoresis. The probes were labeled with $\left[{ }^{32} \mathrm{P}\right] \mathrm{dCTP}$ by random priming (Feinberg and Vogelstein 1983). After hybridization, membranes were washed twice in $2 \times \mathrm{SSC}(1 \times \mathrm{SSC}$ is $0.15 \mathrm{M} \mathrm{NaCl}$ plus 0.015 M sodium citrate), $0.1 \%$ SDS (sodium dodecyl sulfate) for 15 
min each time at $42^{\circ} \mathrm{C}$, and twice in $0.5 \times \mathrm{SSC}, 0.1 \%$ SDS at $42^{\circ} \mathrm{C}, 15 \mathrm{~min}$ each time. Quantification of hybridizing bands was performed with a PhosphoImager (Molecular Dynamics, Sunnyvale, CA), equipped with ImageQuant software supplied by the manufacturer, after $24 \mathrm{~h}$ of exposure. Background hybridization was measured by sampling membrane areas outside the lanes, and was subtracted from the signal from the hybridizing bands with ImageQuant software. Data of signal intensities (in arbitrary units) were normalized with respect to the amount of poly(A) ${ }^{+}$RNA loaded in each lane. Normalization was based on hybridization with a ${ }^{32} \mathrm{P}$-labeled poly-U oligonucleotide. Data are presented as the average of relative signal intensities in three experiments, assigning a $100 \%$ value to the $F$. graminearum-inoculated Sumai 3 lane with the strongest hybridization intensity.

\section{Defense response gene probes.}

Six defense response gene cDNAs were used as probes, including two from wheat, peroxidase (plasmid pOX381; accession number X56011; Rebman et al. 1991a), and PR-1-2 (Molina et al. 1999; accession number EMBL AJ007349), and four from barley (Gregersen et al. 1997), including PR-2 or $\beta$ 1,3-glucanase (pBH72.I1; accession number not available), acidic PR-3 or chitinase type II (HvCht2a; EMBL accession number X78671), PR-4 (pBH72-F6; EMBL accession number Y10814), and acidic PR-5 or thaumatin-like protein (pBH72C6; accession number not available). All these genes were originally isolated by differential screening of cDNA libraries made from powdery mildew-infected barley or wheat leaves, and transcripts for all these genes were shown to accumulate during powdery mildew infection. Each of these genes was used as a hybridization probe for the three experiments described, with the exception of peroxidase, which was used as a probe in two experiments.

\section{LITERATURE CITED}

Adams, J. F. 1921. Observations on wheat scab in Pennsylvania and its pathological history. Phytopathology 11:115-124.

Atanasoff, D. 1920. Fusarial blight (scab) of wheat and other cereals. J. Agric. Res. 20:1-32.

Bai, G., Kolb, F. L., Shaner, G., and Domier, L. L. 1999. Amplified fragment length polymorphism markers linked to a major quantitative trait locus controlling scab resistance in wheat. Phytopathology 89: 343-348.

Bai, G. H., and Shaner, G. 1994. Scab of wheat: Prospects for control. Plant Dis. 78:760-766.

Bennett, F. T. 1931. Gibberella saubinetti (Mont.) Sacc. on British cereals. II. Anal. Appl. Biol. 18:158-176.

Boshoff, W. H. P., Pretorius, Z. A., Swart, W. J., and Jacobs, A. S. 1996. A comparison of scab development in wheat infected by Fusarium graminearum and Fusarium crookwellense. (Abstr.) Phytopathology 86: (Suppl.) S58.

Bowles, D. J. 1990. Defense-related proteins in higher plants. Annu. Rev. Biochem. 59:873-907.

Boyd, L. A., Smith, P. H., Green, R. M., and Brown, J. K. M. 1994. The relationship between the expression of defense-related genes and mildew development in barley. Mol. Plant-Microbe Interact. 7:401-410.

Cappellini, R. A., and Peterson, J. L. 1971. pH, nutrients and macrospore germination in Gibberella zeae. Mycologia 63:641-643.

Caruso, C., Caporale, C., Chilosi, G., Vacca, F., Bertini, L., Magro, P., Poerio, E., and Buonocore, V. 1996. Structural and antifungal properties of a pathogenesis-related protein from wheat kernel. J. Protein Chem. 15:35-44.

Caruso, C., Chilosi, G., Caporale, C., Leonardi, L., Bertini, L., Magro, P., and Buonocore, V. 1999. Induction of pathogenesis-related pro- teins in germinating wheat seeds infected with Fusarium culmorum. Plant Sci. 140:87-97.

Carver, T. L. W., Robbins, M. P., and Zeyen, R. J. 1991. Effects of two PAL inhibitors on the susceptibility and localized autofluorescent host cell responses of oat leaves attacked by Erysiphe graminis DC. Physiol. Mol. Plant Pathol. 39:269-287.

Casacuberta, J. M., Puigdomenèch, P., and San Segundo, B. 1991. A gene coding for a basic pathogenesis-related (PR-like) protein from Zea mays. Molecular cloning and induction by a fungus (Fusarium moniliforme) in germinating maize seeds. Plant Mol. Biol. 16:527536.

Clark, T. A., Zeyen, R. J., Carver, T. L. W., Smith, A. G, and Bushnell, W. R. 1995. Epidermal cell cytoplasmic events and response gene transcript accumulation during Erysiphe graminis attack in isogenic lines differing at the Ml-o locus. Physiol. Mol. Plant Physiol. 46:1-16.

Clark, T. A., Zeyen, R. J., Smith, A. G., Bushnell, W. R., Szabo, L. J., and Vance, C. P. 1993. Host response gene transcript accumulation in relation to visible cytological events during Erysiphe graminis attack in isogenic barley lines differing at the Ml- $a$ locus. Physiol. Mol. Plant Pathol. 43:283-298.

Cordero, M. J., Raventos, D., and San Segundo, B. 1992. Induction of PR proteins in germinating maize seeds infected with the fungus Fusarium moniliforme. Mol. Plant Pathol. 41:189-200.

Cutt, J. R., and Klessig, D. F. 1992. Pathogenesis-related proteins. Pages 209-243 in: Genes Involved in Plant Defense. T. Boller and F. Meins, eds. Springer-Verlag, Vienna.

Darken, M. A. 1961. Applications of fluorescent brighteners in biological techniques. Science 133:1704-1705.

De Vries, S. C., Springer, J., and Wessels, J. G. H. 1982. Diversity of abundant mRNA sequences and patterns of protein synthesis in etiolated and greened pea seedlings. Planta 156:129-135.

Dickson, J. G., Johan, H., and Wineland, G. 1921. Second progress report on the fusarium blight (scab) of wheat. Phytopathology 11:35.

Dixon, R. A., and Lamb, C. J. 1990. Molecular communication in interactions between plants and microbial pathogens. Annu. Rev. Plant Physiol. Plant Mol. Biol. 41:339-367.

Esau, K. 1965. The flower. Pages 572-573 in: Plant Anatomy. J. Wiley and Sons, New York.

Faris, J. D., Li, W. L., Liu, D. J., Chen, P. D., and Gill, B. S. 1999. Candidate gene analysis of quantitative disease resistance in wheat. Theor. Appl. Genet. 98:219-225.

Feinberg, A. P., and Vogelstein, B. 1983. A technique for radiolabeling DNA restriction endonuclease fragments to high specific activity. Anal. Biochem. 132:6-13.

Goates, B. J. 1988. Histology of infection of wheat by Tilletia indica, the Karnal bunt pathogen. Phytopathology 78:1434-1441.

Gregersen, P. L., Thordal-Christensen, H., Forster, H., and Collinge, D. B. 1997. Differential gene transcript accumulation in barley leaf epidermis and mesophyll in response to attack by Blumeria graminis $\mathrm{f}$. sp. hordei (syn. Erysiphe graminis f. sp. hordei). Physiol. Mol. Plant Pathol. 51:85-97.

Hammond-Kosak, K. E., and Jones, J. D. G. 1996. Resistance-gene dependent plant defense responses. Plant Cell 8:1773-1791.

Hodson, M. J., and Sangster, A. G. 1988a. Silica deposition in the inflorescence bracts of wheat (Triticum aestivum). I. Scanning electron microscopy and light microscopy. Can. J. Bot. 66:829-838.

Hodson, M. J., and Sangster, A. G. 1988b. Silica deposition in the inflorescence bracts of wheat (Triticum aestivum). II. X-ray microanalysis and backscattered electron imaging. Can. J. Bot. 67:281-287.

Ikeda, T., Higashi, S., and Ono, S. 1955. Studies on the resistance of wheat and barley varieties to ear scab disease (Gibberella zeae). III. Studies on varietal difference in relation to the enlargement of scab spots. Bull. Div. Plant Breeding, Tokai-Kinki Agric. Stn. (Abstr. in Rev. Appl. Mycol. 35:760, 1956).

Ireta-Moreno, J., and Bekele, G. T. 1989. Histopatología de la penetración de Fusarium graminearum Schw. en trigo. Pages 85-89 in: Taller sobre la Fusariosis de la Espiga en América del Sur. M. M. Kohli, ed. CIMMYT, Lisboa, México.

Koga, H. 1995. An electron microscopy study of the infection of spikelets of rice by Pyricularia oryzae. J. Phytopathol. 143:439-445.

Köller, W., Parker, D. M., and Becker, C M. 1991. Role of cutinase in the penetration of apple leaves by Venturia inaequalis. Phytopathology 81:1375-1379.

Kuck, K. H., Tiburzy, R., Hanssler, G., and Reisener, H. J. 1981. Visu- 
alization of rust haustoria in wheat leaves by using fluorochromes. Physiol. Plant Pathol. 19:439-441.

Lin, K.-C., Bushnell, W. R., Szabo, L. J., and Smith, A. G. 1996. Isolation and expression of a host response gene family encoding thaumatin-like proteins in incompatible oat-stem rust fungus interactions. Mol. Plant-Microbe Interact. 9:511-522.

Lotan, T., Ori, N., and Fluhr, R. 1989. Pathogenesis-related proteins are developmentally regulated in tobacco flowers. Plant Cell 1:881-887.

Malalasekera, R. A. P., Sanderson, F. R., and Colhoun, J. 1973. Fusarium disease of cereals. IX. Penetration and invasion of wheat seedlings by Fusarium culmorum and F. nivale. Trans. Br. Mycol. Soc. 60:453462.

McMullen, M., Jones, R., and Gallenberg, D. 1997. Scab of wheat and barley: A re-emerging disease of devastating impact. Plant Dis. 81: 1340-1348.

Mesterhazy, A. 1995. Types and components of resistance to Fusarium head blight of wheat. Plant Breed. 114:377-386.

Miller, J. D., Young, J. C., and Arnison, P. G. 1986. Degradation of deoxynivalenol by suspension cultures of the Fusarium head blight resistant wheat cultivar Frontana. Can. J. Plant Pathol. 8:147-150.

Molina, A., Görlach, J., Volrath, S., and Ryals, J. 1999. Wheat genes encoding two types of PR-1 proteins are pathogen inducible, but do not respond to activators of systemic acquired resistance. Mol. PlantMicrobe Interact. 12:53-58.

Morris, S. W., Vernooij, B., Titatarn, S., Starrett, M., Thomas, S., Wiltse, C. C., Frederiksen, R. A., Bhandhufalck, A., Hulbert, S., and Uknes, S. 1998. Induced resistance responses in maize. Mol. Plant-Microbe Interact. 11:643-658.

Muradov, A., Petrasovits, L., Davidson, A., and Scott, K. J. 1993. A cDNA clone for a pathogenesis-related protein 1 from barley. Plant Mol. Biol. 23:439-442.

Neale, A. D., Wahleithner, J. A., Lund, M., Bonnelt, H. T., Kelly, A., Meeks-Wagner, D., Peacock, W. J., and Dennis, E. S. 1990. Chitinase, $\beta$-1,3-glucanase, osmotin, and extensin are expressed in tobacco explants during flower formation. Plant Cell 2:673-684.

Pennypacker, B. W. 1981. Anatomical changes involved in the pathogenesis of plants by Fusarium. Pages 400-408 in: Fusarium. Disease, Biology, and Taxonomy. P. E. Nelson, T. A. Tousson, and R. J. Cook, eds. Pennsylvania State University Press, University Park.

Percival, J. 1921. The inflorescence. Pages 100-110 in: The Wheat Plant. Duckworth, London.

Pugh, G. W., Johan, H., and Dickson, J. G. 1933. Factors affecting infection of wheat heads by Gibberella saubinetti. J. Agric. Res. 46: 771-797.

Rebman, G., Hertig, C., Bull, J., Mauch, F., and Dudler, R. 1991a. Cloning and sequencing of cDNAs encoding a pathogen-induced putative peroxidase of wheat (Triticum aestivum L.). Plant Mol. Biol. 16: 329-331.

Rebman, G., Mauch, F., and Dudler, R. 1991b. Sequence of a wheat cDNA encoding a pathogen-induced thaumatin-like protein. Plant Mol. Biol. 17:283-285.

Rohringer, R., Kim, W. K., Samborski, D. J., and Howes, N. K. 1977. Calcofluor: An optical brightener for fluorescence microscopy of fungal plant parasites in leaves. Phytopathology 67:808-810.

Schaffrath, U., Freydl, E., and Dudler, R. 1997. Evidence for different signaling pathways activated by inducers of acquired resistance in wheat. Mol. Plant-Microbe Interact. 10:779-783.

Schroeder, H. W., and Christensen, J. J. 1963. Factors affecting resistance of wheat to scab caused by Gibberella zeae. Phytopathology 53: 831-838.

Schweizer, P., Hunziker, W., and Mösinger, E. 1989. cDNA cloning, in vitro transcription and partial sequence analysis of mRNA from winter wheat (Triticum aestivum L.) with induced resistance to Erysiphe graminis f. sp. tritici. Plant Mol. Biol. 12:643-654.

Singh, R. P., Ma, H., and Rajaram, S. 1995. Genetic analysis of resistance to scab in spring wheat cultivar Frontana. Plant Dis. 79:238240.

Stevens, C., Titarenko, E., Hargreaves, J. A., and Gurr, S. 1996. Defense-related gene activation during an incompatible interaction between Stagonospora (Septoria) nodorum and barley (Hordeum vulgare L.) coleoptile cells. Plant Mol. Biol. 31:741-749.

Sutton, J. C. 1982. Epidemiology of wheat head blight and maize ear rot caused by Fusarium graminearum. Trans. Br. Mycol. Soc. 70:187192.

Tu, C. 1930. Physiological specialization in Fusarium species causing head blight of small grains. Minn. Agric. Exp. Stn. Tech. Bull. 74.

Tuite, J., Shaner, G., and Everson, R. J. 1990. Wheat scab in soft red winter wheat in Indiana in 1986 and its relation to some quality measurements. Plant Dis. 74:959-962.

Valè, G. P., Torrigiani, E., Gatti, A., Delogu, G., Porta-Puglia, A., Vannacci, G., and Cattivelli, L. 1994. Activation of genes in barley roots in response to infection by two Drechslera graminea isolates. Physiol. Mol. Plant Pathol. 44:207-215.

Van Ginkel, M., Van Der Schaar, W., Zhuping, Y., and Rajaram, S. 1996. Inheritance of resistance to scab in two wheat cultivars from Brazil and China. Plant Dis. 80:863-867.

Vigers, A. J., Wiedemann, S., Roberts, W. K., Legrand, M., Selitrennikoff, C. P., and Fritig, B. 1992. Thaumatin-like pathogenesis-related proteins are antifungal. Plant Sci. 83:155-161.

Wagner, K., Hitz-Hermann, L., Seng, J. M., and Gessler, C. 1988. Cellulolytic ability of the scab fungus, Venturia inaequalis. J. Phytopathol. 123:217-221.

Waldron, B. L., Moreno-Sevilla, B., Anderson, J. A., Stack, R. W., and Frohberg, R. C. 1999. RFLP mapping of QTL for Fusarium head blight resistance in wheat. Crop Sci. 39:805-811.

Wang, Y. Z., and Miller, J. D. 1988. Screening techniques and sources of resistance to Fusarium head blight. Pages 239-250 in: Wheat Production Constraints in Tropical Environments. A. R. Klatt, ed. CIMMYT, Lisboa, Mexico.

Wheeler, H. 1977. Ultrastructure of penetration by Helminthosporium maydis. Physiol. Plant Pathol. 11:171-178.

Wilcoxson, R. D., Busch, R. H., and Ozmon, E. A. 1992. Fusarium head blight resistance in spring wheat cultivars. Plant Dis. 76:658-661.

Wilcoxson, R. D., Bekele, G. T., and Etebarian, H. R. 1993. Reaction of spring wheat cultivars to head blight. Biol. Cult. Tests Control Plant Dis. 8:88.

Williamson, P. M., Sivasithamparam, and Cowling, W. A. 1991. Formation of subcuticular coralloid hyphae by Phomopsis leptostromiformis upon latent infection of narrow-leafed lupins. Plant Dis. 75:10231026.

Zadoks, J. C., Chang, T. T., and Konzak, C. F. 1974. A decimal code for the growth stages of cereals. Weed Res. 14:415-421. 